\title{
El palacio de los Páez de Castillejo. El ascenso social de un linaje
}

\author{
The palace of the Páez de Castillejo. \\ The social climbing of a lineage
}

María Ángeles JORDANO BARBUDO

Universidad de Córdoba

Recibido: 15-IV-2017

Aceptado: 25-V-2017

RESUMEN: A través de la documentación conservada y del análisis de los espacios, elementos arquitectónicos y ornamentales, es posible seguir la transformación de unas primeras casas, en las que aún pervive la tradición doméstica andalusí, en un palacio renacentista, bajo la dirección de uno de los arquitectos más interesantes y activos de Andalucía en ese momento, Hernán Ruiz II, quien culminará la nueva apariencia de la mansión con una portada que sella en Córdoba una evolución tipológica y al mismo tiempo consagra al linaje de los Páez de Castillejo gracias a un programa iconográfico que pivota en torno a la exaltación de las virtudes del guerrero como paradigma del ideal humanista.

Palabras clave: Hernán Ruiz II, Guerrero, Renacimiento, Mudéjar, Portada, Alegoría.

ABSTRACT: Preserved documents, architectural and ornamental elements as well as a profound analysis of spaces, may very well serve to determine transformation processes of several original houses belonging to a Renaissance palace in which the Andalusian domestic tradition is nowadays still alive. Hernán Ruiz II, one of the most valuable and active architects in Andalusia at that time, would be the one in charge of such transformations. His major achievements include the new appearance given to the portal of the palace that would imply an innovative typology in Córdoba. Moreover, the usage of a specific iconographic technic consisting on the exaltation of the warrior's qualities as a paradigm of the humanist ideal would suppose the definitive tool consecrating the Paez de Castillejo linage.

Keywords: Hernán Ruiz II, Warrior, Renaissance, Mudejar, Portal, Allegory.

\section{EL ENCLAVE}

En 2017 el Museo Arqueológico de Córdoba celebra el 150 aniversario de su creación ${ }^{1}$. Tras largos años de traslados por dis-

${ }^{1}$ El presente artículo se ha elaborado en el marco del proyecto de investigación "Nobles judeoconversos (II). La proyección patrimonial de las élites judeo conversas andaluzas" (HAR2015-68577), financiado por el tintas casas², finalmente, en 1962, se inauguró la actual sede en el palacio de los Páez de Castillejo, uno de los linajes más importan-

\section{Ministerio de Economía y Competitividad.}

2 Sobre el proceso de transformación en época reciente, vid., entre otras, M. D. BAENA ALCÁNTARA, “El Museo Arqueológico de Córdoba. Un museo en transformación”, Museos.es, 7-8, 2011-2012, pp. 308-319. 


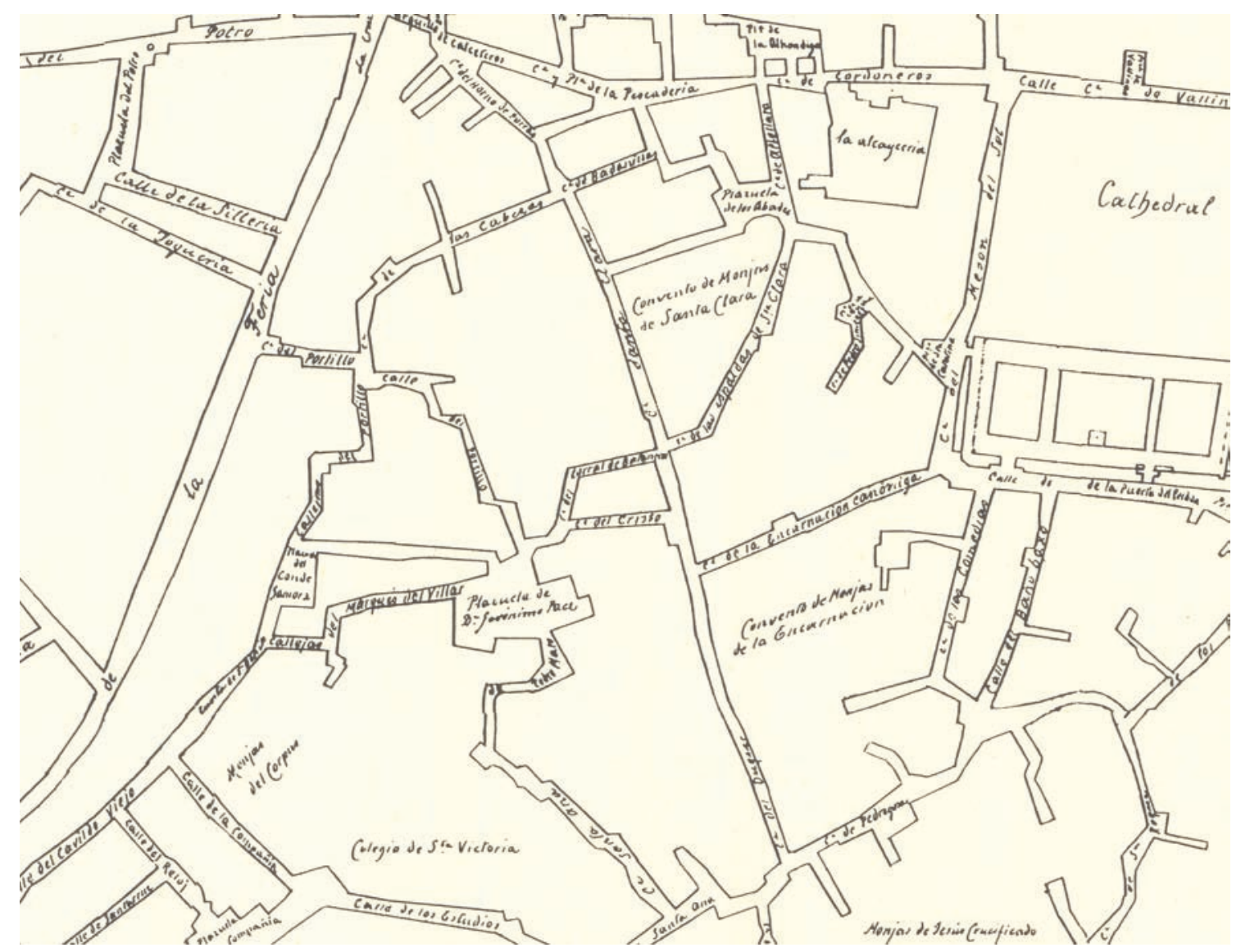

- Fig. 1. Barón de Karvinsky. Detalle del Plano de los Franceses. 1811. Archivo Municipal de Córdoba. Planos de Córdoba. MU 001-001.

tes de la ciudad, que vivió una época de esplendor desde finales de la Baja Edad Media hasta finales del siglo XVII. A través de los planos de Córdoba, desde el más antiguo, conocido como el de los Franceses (1811) (Fig. 1), se hace evidente la relevancia del lugar en que se encuentra dicho palacio; no en vano fue éste emplazamiento del teatro romano (15 a.C.-15 d.C.), aprovechando el fuerte desnivel del terreno ${ }^{3}$. Sus restos están

\footnotetext{
${ }^{3}$ Cfr. a este respecto y solo por citar algunas referencias: M. D. BAENA ALCÁNTARA, "El teatro romano de Córdoba", Mus-A: Revista de los museos de Andalucía, 2, 2003, pp. 157-161. J. F. MURILLO y F. A. ARAQUE, "Informe preliminar de las excavaciones arqueológicas realizadas en el solar destinado a ampliación del Museo Arqueológico Provincial de Córdoba", Anuario Arqueológico de Andalucía 1987, III, Actividades de urgencia, 1990, pp. 203-204. Á. VENTURA et alii, "Análisis arqueológico de la Córdoba romana: resultados e hipótesis de la investigación", en P. LEÓN (ed.), Colonia Patricia Corduba. Una reflexión
}

integrados en la ampliación del museo y son visibles también en el Patio Norte.

Las primeras viviendas surgen en época visigoda, pues se encontraron trozos de cascote y cerámica en el relleno del patio de la Noria. En el s. VII se levanta un muro de contención, recrecido en época musulmana y cristiana, que dará lugar a la Cuesta de Pero Mato. También hay constancia de presencia musulmana ${ }^{4}$. En el siglo XII aparece este en-

arqueológica, Córdoba, 1996, pp. 87-118. Á. VENTURA, "La recuperación de la Córdoba romana: los edificios de espectáculos", en T. NOGALES BASARRATE (coord.), Vivir las ciudades históricas, Coloquio Internacional sobre ciudades modernas superpuestas a las antiguas, 10 años de investigación, Mérida, 1997, pp. 33-54. J. SÁNCHEZ VELASCO, “El acceso Norte al teatro romano de Córdoba: secuencia estratigráfica y estudio de materiales", Anales de Arqueología Cordobesa, 10, 1999, pp. 115-159.

${ }^{4}$ Ana María Vicent, antigua directora, halló el 
torno como un espacio urbano configurado. La Cuesta de Pero Mato es una calle pública y el espacio del teatro aparece ocupado por casas.

Afirmaba Muñoz Vázquez que en la fachada posterior del palacio que da al patio de la Noria, construido con tapial alternado con mampostería y ladrillo, justamente "en el muro frente a éste, que forma una de las habitaciones de la parte alta, se halla un arco almohade, de ladrillo, el cual ha sido enlucido en la actual restauración" ${ }^{\prime 5}$. Los intentos por localizar dicho arco han sido en vano.

El 29 de junio de 1236 Fernando III conquista Córdoba. En este momento se conoce el lugar como plaza de los Paraísos $^{6}$, sin que se sepa la razón de este nombre, aunque Muñoz Vázquez argumentaba que se debía a la existencia de un árbol de esta especie en ella7. A partir de 1540 fue llamada de Luis Páez de Castillejo ${ }^{8}$, y desde 1680 ya fue conocida con el nombre actual, la plaza de Jerónimo Páez de Castillejo9 .

Ocupa un solar de forma predominantemente rectangular, delimitado al oeste, hacia donde mira su fachada principal, por la

tesorillo compuesto de piezas de hueso exhibido en sala. Del siglo XI es el descubierto en 1986, constituido por 620 dirhemes de plata.

${ }^{5}$ M. MUÑOZ VÁZQUEZ, “Casas solariegas. Palacio de los Páez de Castillejo, Plaza de los Paraísos y Cuesta de Peramato", Boletín de la Real Academia de Córdoba, 84, 1962, pp. 31-66.

${ }^{6}$ J. M. ESCOBAR CAMACHO, Córdoba en la Baja Edad Media. (Evolución urbana de la ciudad), Córdoba, 1989, p. 139.

${ }^{7}$ M. MUÑ̃Z VÁZQUEZ, Op. cit., p. 31. Quizá fuera una Melia Serpenvirens, conocida como árbol del Paraíso, también llamado alilaila.

8 Sobre el linaje de los Páez de Castillejo, cfr. Real Academia de la Historia (en adelante RAH), A. MORALES, Linaje de los Páez de Castillejo, sacado de la Historia de Córdoba, 9/331, fols. 227v.-230r. Consultado el 23 de febrero de 2017. URL: http://bibliotecadigital.rah. es/dgbrah/i18n/consulta/registro.cmd?id=57184

9 T. RAMÍREZ DE ARELLANO Y GUTIÉRREZ, Paseos por Córdoba, o sean apuntes para su historia, Córdoba, 1973, p. 554. plaza de Jerónimo Páez; al sureste por la calle Marqués del Villar, que en 1481 se conocía como barrera del Comendador Moscoso, la cual haciendo un recodo se dirige al este, tramo antiguamente denominado Costanilla de Baena; finalmente, hacia el norte el solar se perfila irregularmente a causa del fuerte desnivel del terreno, limitando con la Cuesta de Peromato (Fig. 2).

La calle Antonio del Castillo fue en el pasado la calle del Paraíso o Sucia ${ }^{10}$. En cuanto a la cuesta de Peromato, en la documentación bajomedieval se hace alusión a una calleja en la plaza "que sale a la iglesia de Santa Agna"11.

Las otras dos calles que confluyen en la plaza son la del Horno del Cristo y la calle Mascarones, actual Julio Romero de Torres, que recibía tal nombre por encontrarse en ella la casa de los Mohedano de Saavedra, del s. XVI, con dos guerreros en su fachada.

\section{LA REGULARIZACIÓN DE LA PLA- ZA DE LOS PARAÍSOS Y SU ENTOR- $\mathrm{NO}$}

A finales del siglo XIX la ciudad asiste a un significativo proceso urbanístico que afecta a este entorno. Por un lado, se aborda la exteriorización de las casas, lo cual se observa en la determinación de abrir nuevos vanos recayentes a la calle o agrandar los ya existentes, quebrando así el ensimismamiento heredado de la arquitectura andalusí, cuya vida se tejía en torno al patio. Asimismo, existió un afán por regularizar vías y plazas, lo que se refleja meridianamente en la plaza de Jerónimo Páez. La última alineación de las calles en esta zona tuvo lugar en $1889^{12}$. Poco antes, en 1888, se lleva a cabo la reforma de fachada del $n^{0} 6^{13}$; concretamente, se

${ }^{10}$ Ibídem.

${ }^{11}$ J. M. ESCOBAR CAMACHO, Op. cit., p. 139, nota 139, citando Archivo de la Catedral de Córdoba (en adelante ACC), Caja E, Documento 293a, s.fol.

${ }^{12}$ Diario Córdoba, martes, 2 de octubre de 1990, p. 9.

13 Archivo Municipal de Córdoba (en adelante 


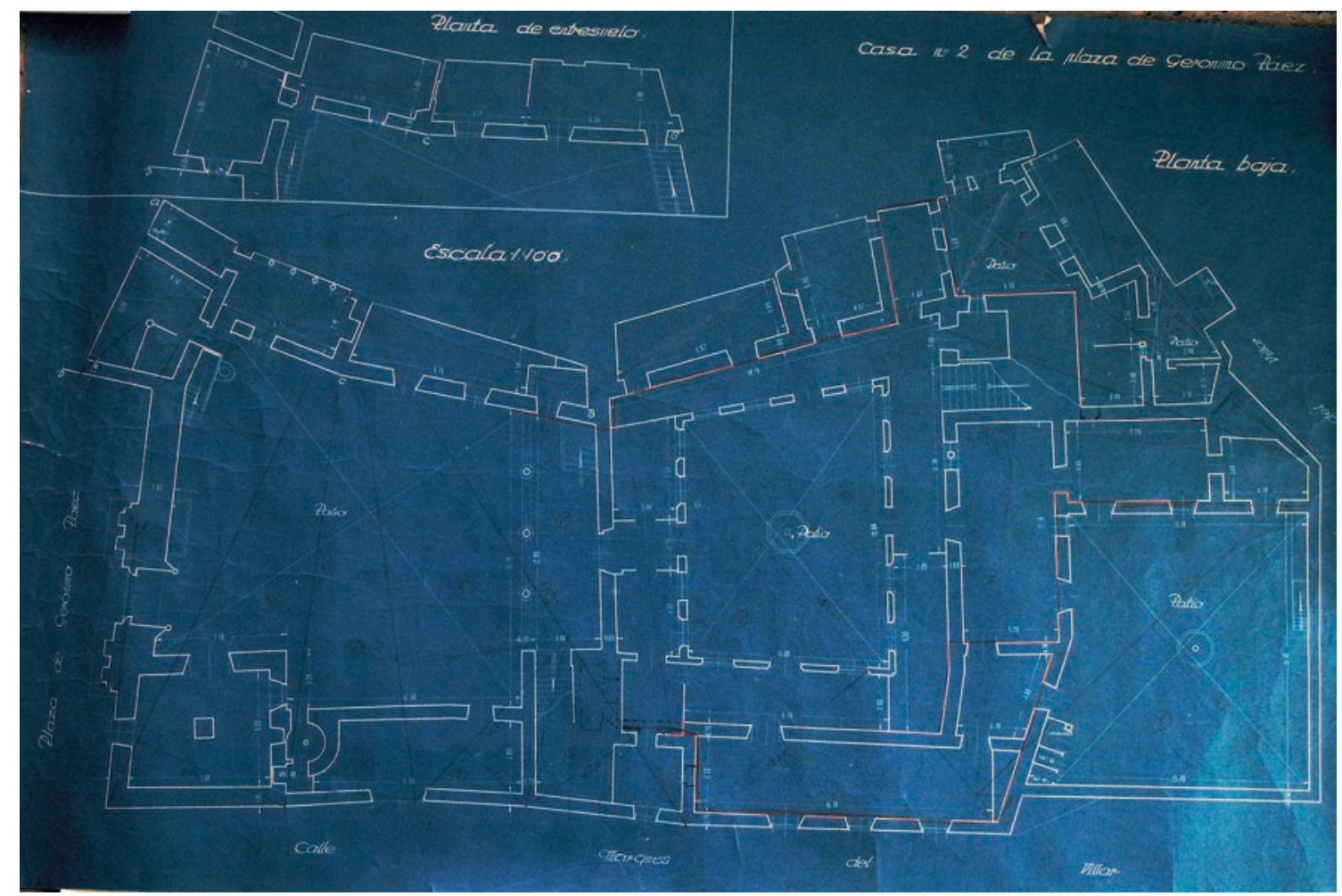

- Fig. 2. Félix Hernández. Planta del palacio de los Páez de Castillejo. Ca. 1946. (c) Museo Arqueológico de Córdoba.

trataba del inmueble con fachada a la plaza y a la Cuesta de Peromato. Se agrandaron los huecos de ventanas ubicados en planta baja y balcones de la alta, y se construyó una casa-cochera hacia la cuesta, consecuencia de la expansión del uso de vehículos a motor.

Años después, en 1911, se reforma el no 1 de la plaza "en la parte que corresponde a la calle del Castillo". En primer lugar, se eliminaron dos quiebros que proyectaban un triángulo saliente de $24 \mathrm{~m}^{2}$, con lo cual la vía pública ganaba espacio y diafanidad, y se eliminaba un rincón "basurero". Al mismo tiempo, se ampliaron los cinco vanos existentes y se añadió un sotabanco ${ }^{14}$.

Se constata que la ampliación de vanos no es un hecho aislado y llega al edificio que nos ocupa. En 1929, en el no 2 de la plaza se

AMCO), 319/62. Incluye un plano de alzado.

${ }^{14}$ Ibídem, 331/16. Ayuntamiento de Córdoba, Sección de Fomento (10/06/1911). agranda una ventana alta que recae a la calle Marqués del Villar ${ }^{15}$.

Por estos años el arquitecto Félix Hernández realizaba la reforma de la casa en la calle Rey Heredia, 13, también conocida como casas del infante don Enrique y, posteriormente, de los Venegas. Esta casa fue adquirida por Elías J. Nahmias, quien encargó a don Félix la reforma de la fachada recayente a la plaza. Se conserva la planta, así como dibujos del arquitecto. En 1967 este conocido filántropo pidió autorización para una ligera rectificación de la línea de fachada -de lo cual adjuntaba un plano-, "en el tramo de fachada a la referida plaza a que la mencionada edificación ha de afectar en su día, rectificación con la que quedaría eliminado, con indudable mejora de aspecto del lugar de que se trata, el tacón, nada favorable estéticamente, existente en el indicado paraje de la vía pública y que habrá de suponer identidad, y consiguientemente permuta, entre la

\footnotetext{
${ }^{15}$ Ibídem, 365/14. (7/01/1929)
} 
porción de terreno que se ceda y la que se gane, por una y otra parte"16.

En la plaza se hallan una serie de piezas arqueológicas que pertenecen al museo. Están situadas en este lugar desde 1977 y se trata fundamentalmente de restos arquitectónicos. En 1990 el arquitecto Juan Serrano, junto con Rafael García Castejón, puso en marcha un proyecto de remodelación de la plaza que incluía colocar la fuente romana hallada en la calle Saravia, no 3 , lo que no se llevó a efecto ${ }^{17}$.

La Cuesta de Peromato fue objeto de remodelación en 1958, consecuencia del PGOU de tal año ${ }^{18}$, aunque no aparecía incluida en él. Se creó el pequeño jardín que hay en la meseta antes de llegar a la plaza de Jerónimo Páez". En la "Ordenanza especial para la zona histórico-artística" del mismo año ya se establecía la obligación de incluir un patio principal en las casas, con el fin de "conservar el carácter de la zona históricoartística y de no aumentar su densidad de población" ${ }^{20}$.

\section{LA CONFORMACIÓN DE UN PALA- CIO Y LA CONFIGURACIÓN DE UN LINAJE}

El germen del solar de los Páez parece que fue el palacio del alfaquí Ybrahim Ben Nasçer, según noticia que daba Muñoz Vázquez al referirse al repartimiento hecho por Fernando III, quien lo entregó a Martín Ruiz

${ }^{16}$ Museo Arqueológico de Córdoba (en adelante MACO), Expediente E, Legajo 4, Carpeta 12.

17 Ibídem, Archivo Sala "El Alcaide", Caja s/n, Carpeta "Piezas de este Museo instaladas en la plaza de Jerónimo Páez. Obras de remodelación de la plaza".

${ }^{18} \mathrm{~J}$. REBOLLO DICENTA, Plan General de Ordenación Urbana de Córdoba, 1958 (aprobado el3/12/1958), Archivo de la Gerencia Municipal de Urbanismo (en adelante AGMU), Documento C-342.

19 ÍDEM, Plan de Ordenación Urbana de Córdoba y su puesta en práctica, Memoria, t. 1, p. 5, 1958. AGMU, Documento C-3502/2.

${ }^{20}$ Ibídem. Incluida en el tomo I, artículo 37 "Casas con patio". de la Cerca en recompensa por su ayuda en la conquista de Córdoba ${ }^{21}$.

Al morir Martín Ruiz el palacio pasó a su hijo homónimo, y de éste a su hija Toda Martínez $^{22}$. Además de estas casas principales, donde doña Toda tenía su morada, ella llegó a tener otras "casas pequeñas" que lindaban con las suyas y con las de Juan Pérez (Páez), fraile de la orden de Santiago. Dichas casas daban a la plaza de los Paraísos. En su testamento de 1343 dejó al cabildo dichas casas, "con condición que por su vida las desfrutasen Miguel Pérez y Constanza Martínez"23. Dispuso mandas para ser enterrada en la capilla de San Benito de la iglesia de Santa María (catedral), que pertenecía a su suegro Ruiz Díaz ${ }^{24}$.

Posteriormente estas casas principales en la collación de Santa María ${ }^{25}$ fueron a re-

21 “Do e otorgo a vos don Martín Ruiz de la Cerca e a vuestros hijos e a vuestras fijas e a todos vuestros sucesores que serán después de vos. Dovo e otorgo a vos en Córdoba unas casas que son dentro de la villa las que fueron de Ben Nascer en la plaza de los Paraísos, con su patio alto para las mujeres [...]. Facta carta apud Corduva Rex Christus doce días de mayo. Era MCCLXXX". Transcrito en M. MUÑOZ VÁZQUEZ, Op. cit., p. 39. No cita la fuente, sino un trabajo suyo que permanece inédito ("Repartimiento de Córdoba por el Rey D. Fernando III el Santo"), por lo que no ha sido posible buscar la referencia. En otra publicación parcial sobre el repartimiento no hace alusión a tal palacio, vid. M. MUÑOZ VÁZQUEZ, "Historia del repartimiento urbano de Córdoba", Boletín de la Real Academia de Córdoba, XXXII, 81, 1961, p. 88. Escobar Camacho cita los nombres de los primeros vecinos que se asentaron en las collaciones, bien como vecinos, bien como propietarios, y, en la de Santa María, figura "Martín Ruiz el del obispo" (J. M. ESCOBAR CAMACHO, "Notas sobre el repartimiento de Córdoba", Boletín de la Real Academia de Córdoba, LV, 107, 1984, pp. 167-168), que no sabemos si sería este Martín Ruiz de la Cerca.

$$
{ }^{22} \text { M. MUÑOZ VÁZQUEZ, “Casas solariegas...”, p. }
$$
40 .

${ }^{23}$ ACC, Caja E, Legajo 12, número 291, copia del testamento de Toda Martínez (Lucena, 29 de agosto de la era de 1381).

$$
{ }^{24} \text { M. MUÑOZ VÁZQUEZ, “Casas solariegas...”, p. }
$$
256.

${ }^{25}$ El cabildo era uno de los principales propietarios de la collación de Santa María, ya que los inmuebles 


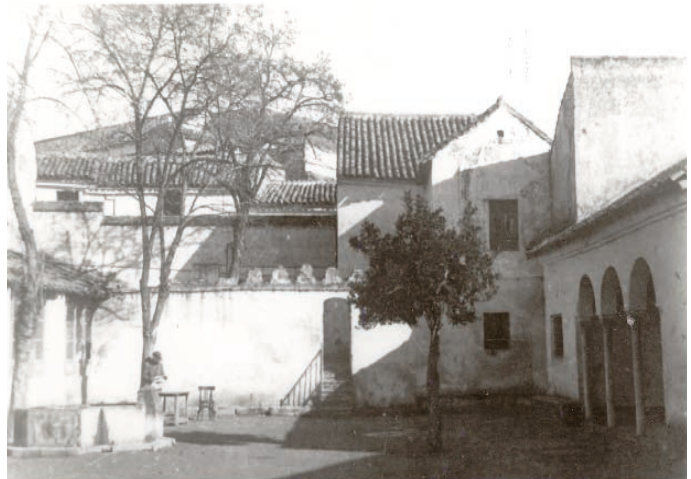

- Fig. 3. Patio norte del palacio. Siglo XV. (C) Museo Arqueológico de Córdoba.

caer en el canónigo Francisco Pablo, si bien en 1348 este las revirtió nuevamente al cabildo. El documento se revela sumamente interesante, pues en dichas casas "había un Palaziello, y un portal delante deel, y otra casa a mano izquierda, un corral y un pozo con otra casa pequeña, que tienen la puerta a la calle y se tienen con casas de Juan Páez, fraile de la orden de Santiago y la dicha Plaza; y con otras casas de dicho Francisco Pablo, cuias casas dio al cabildo porque le hiciese dos sepulturas ante la imagen de Santa María que él había mandado hacer, para ser enterrado, y sus descendientes" 26 .

urbanos estuvieron mayoritariamente en manos de la Iglesia (M. I. CASTILLEJO CUENCA, "Los caballeros Veinticuatros de Córdoba a finales del siglo XVII", Chronica Nova, 22, 1995, p. 42). Concretamente, tenían varias casas en la plaza de los Paraísos; así, en 1345 el deán y el cabildo dieron a Juan Esteban el correero y a su mujer "una casa que es donde los Paraísos" a cambio de otras casas "que son donde el horno de Calatrava". Aquélla casa es la "que nos avemos en esta dicha collación en la plaza que dicen de los paraysos que se tiene con las casas de vuestra morada..." (ACC, Libro de Tablas, fols. 112v.-113r., noticia de 3 de septiembre de la era de 1383). Junto a la casa habitada por el "correero", se encontraba la de Pedro Martín, "compañero que fue desta eglesia". Cuando murió, Juan Esteban y su mujer arrendaron también esta casa, con condición de que al fallecer, deberían devolver las casas al cabildo. Cuando esto ocurrió, las casas fueron habitadas por Teresa González, hija de Juan Ruiz, criado del alcalde Martín Alfonso de Saavedra (ACC, Libro Verde, transcripción e índices de Manuel Nieto Cumplido, Córdoba, 1970, p. 54 (inédito), fol. 42r. en el original).

${ }^{26}$ ACC, Caja E, Legajo 12, número 280. La misma noticia en ACC, E-IV, 284, y en E-IV, 285 copia
De este documento destacamos la referencia a un "palaziello", es decir, un palacio, que sabemos que era la forma en que en los registros quedaba anotada la habitación principal del domicilio. El término palacio se refiere a una estructura que deriva de la tradición doméstica andalusí, caracterizada por una habitación de planta rectangular, usualmente flanqueada por dos alcobas de planta cuadrada y precedida por un pórtico, en este caso el "portal". Igualmente interesante es la alusión al corral y al pozo, también habituales en casas de cierta entidad para tener animales y provisión de agua. No olvidemos, asimismo, que más arriba se hacía alusión al patio alto de las mujeres ${ }^{27}$ (Fig. 3), marcándose así la separación entre sexos en la arquitectura doméstica, como venía siendo tradicional en determinadas circuns$\operatorname{tancias}^{28}$.

En cuanto a las casas pequeñas, es posible saber su delimitación: tenían fachada a la plaza de los Paraísos, y lindaban con las casas de Juan Páez de Aguilar y con las casas de doña Toda. En estas casas vivían en arriendo Pedro Alfonso, albañil, y su mujer. Posteriormente, Toda Martínez las dio al cabildo, que las vendió a Francisco Páez de Castillejo "por dos mill mrs de moneda vieja e entraron en la compra del cortijo de Cañetejo" ${ }^{29}$.

Del estatus de los habitantes de la plaza de los Paraísos son indicativas notables referencias documentales, como que Ferrán Martínez, alguacil mayor de Córdoba, hijo de Juan Martínez y propietario de unas casas en dicha plaza, movido por el interés en tener sepultura en la catedral, le llevó a dárselas al deán y cabildo por escritura otorga-

contemporánea.

${ }^{27}$ Con este nombre se conocía la terraza colmatada que había hacia el norte del inmueble y que fue excavada en el siglo XX.

${ }_{28}$ M. E. DÍEZ JORGE, El arte mudéjar: expresión estética de una convivencia, Granada, 2001, pp. 340-341.

${ }^{29}$ ACC, Libro Verde..., p. 35, fol. 27v. en el original. 
da el 18 de junio de $1390^{30}$. Una vez más, el documento aporta valiosas referencias para conocer lindes y vecinos de las casas, que, según se especifica, estaban en esta plaza, linde de una y otra parte con casas del cabildo ${ }^{31}$. A cambio, éste le asignó, junto a su mujer y descendientes, unas sepulturas dentro de la Iglesia detrás del pilar que está enfrente del altar de Santa María del Pilar, donde Gonzalo Sánchez, compañero, hermano de Ferrant Martínez ${ }^{32}$, "fiço la estoria de Santa Sophia", junto a la sepultura de dicho Gonzalo Sánchez, delante de la figura de Santa Sofía a la mano izquierda y delante de la figura de San Pedro de Luçambort (o Luçembort) ${ }^{33}$.

$\mathrm{Y}$ en este contexto es como llegamos a la noticia que revela la gestación del palacio de los Paéz. Por fin, el 6 de octubre de 1396 el cabildo arrienda por $121 \mathrm{mrs}$ de moneda vieja $^{34}$, de renta anual, a Ferrant Páez una casa que lindaba con la casa de Juan Fernández de Castillejo, padre de Ferrant Páez, una casa del cabildo arrendada a Mateo Sánchez,

${ }^{30}$ ACC, E-IV, 290. M. NIETO CUMPLIDO, Corpus Mediaevale Cordubense, T. 3 y siguientes, inéditos. Agradezco al autor haberme facilitado su consulta.

${ }^{31}$ Una de estas casas del cabildo estaba arrendada a Inés González, viuda de Alvar Rodríguez, hijo del prior Pedro Rodríguez (ACC, Caja E, Legajo 12, número 290). Algún dato más añade el Libro Verde para esta noticia, pues se dice: "Dio Ferrand Martínez, alguacil, heredero de Gonzalo Sánchez, compañero, al cabildo una casa que volvió Pero Alfonso, albañil, en linde con otras que están junto a las casas que tiene Ferrand Páez, a cambio de una sepultura que le dio el cabildo e tiénelas todas Mateo Sánchez, yerno de Pedro Alfonso, por setenta e cinco mrs vendiéronse". Libro Verde..., p. 36, fol. $27 \mathrm{v}$. en el original.

${ }^{32}$ Ferrand Martínez fue heredero de Gonzalo Sánchez. Libro Verde..., fol. 27v. en el original, pp. 35-36.

33 ACC, Caja E, Legajo 12, número 290. Las propiedades del cabildo fueron muy numerosas en el entorno de la plaza de los Paraísos, como se ve en la noticia de que el cabildo arrendó a García Ruiz unas casas en la collación de Santa María, en la calle de los Paraísos, linde de una parte casas de doña Urraca de Saavedra y por otra con casas de Lorenzo Fernández en la barrera". ACC, Caja E, Legajo 12, número 297.

34 "que mandaron hacer los reyes don Sancho y don Fernando". ACC, E-IV, 296. la casa de Ferrant Martínez, alguacil -citada en el párrafo anterior-, y la plaza ${ }^{35}$. Juan Fernández de Castillejo era maestresala del rey y en 1402 figura como regidor ${ }^{36}$. Había heredado sus casas de Ferrant Paéz de Aguilar, del hermano de este, Juan Páez de Aguilar y su mujer Margarita González ${ }^{37}$. Estas casas habían sido originalmente de Juan Páez, fraile de la orden de Santiago.

Paralelamente a estos hechos, se comprueba el ascenso social del linaje. Al tiempo que Juan Fernández de Castillejo era maestresala del rey, comienza a perfilarse otro personaje influyente, Fernán Páez de Castillejo, veinticuatro de Córdoba en $1401^{38}$, si bien un año después es destituido por el doctor Pedro Sánchez, con facultades del rey Enrique III; sin embargo, el mismo nombra a cinco regidores, entre ellos a Juan Fernández de Castillejo ${ }^{39}$, en su política de impulsar esta figura en las ciudades ${ }^{40}$.

El fulgurante ascenso en la escala social de los Páez de Castillejo viene a ser refrendado por la merced que concedió el monarca a Fernán Páez de Castillejo, veinticuatro, y a su hermano de una parte de las salinas de Córdoba ${ }^{41}$. Esta concesión era una de las mejores en la ciudad por los importantes beneficios que reportaba. Pero la consolidación del poder de los Páez se trasluce también en otra noticia, la donación por parte de Juan Fer-

${ }^{35}$ Ibídem.

${ }^{36}$ M. NIETO CUMPLIDO, Op.cit., T. 3 y siguientes, inéditos. ACC, Colección Vázquez Venegas 266, fol. 254 rv.

${ }^{37}$ ACC, Libro Verde..., fol. 27v. en el original, p. 36.

38 Ibídem, Segovia, 20 de agosto de 1401. AMCO, Real Cédula. Salinas, SF/C 00224-001, fol. 233r.

39 Ibídem, (s.1.), 12 de junio de 1402. CVV 266, fol. 254rv. Casa de Cabrera en Córdoba. Córdoba, 1779, p. 123.

40 Sobre esto, vid. J. L. DEL PINO GARCÍA, "El concejo de Córdoba a fines de la Edad Media: estructura interna y política municipal", Historia. Instituciones. Documentos, 20, 1993, pp. 358, 366-367.

${ }^{41}$ ACC, Libro Verde..., Segovia, 20 de agosto de 1401. AMCO, Real Cédula. Salinas, SF/C 00224-001, fol. 233r. 
nández de Castillejo el Moro, Ferrant Páez de Castillejo, maestresala del rey, vecino de la collación de Santa María, y Alfón Fernández de Castillejo, vecino de San Pedro, hijos de Juan Fernández de Castillejo, de unas casas en la collación de San Andrés (calle de los Huevos) ${ }^{42}$ a su tía Urraca Ximénez, mujer de Ruy Méndez de Morales, vecina de la collación de San Miguel, en 140543; donación que revela la posesión de inmuebles en otras collaciones por parte de este linaje.

$\mathrm{Al}$ igual que su padre, Ferrant Páez de Castillejo ocupó el cargo de maestresala del rey. El mismo año Juan Fernández de Castillejo era regidor de la ciudad y figuraba como comprador en la venta del castillo de Almenara, "que es el río ayuso de Gualdalquivir", perteneciente a Juan Alfonso de Sousa, hijo de Vasco Alfonso, alcalde mayor de Córdo$\mathrm{ba}^{44}$, quien, por cierto, también moraba en la plaza de los Paraísos ${ }^{45}$.

A finales de siglo sigue patente la pujanza de esta familia. En noviembre de 1491, el juez de términos de Córdoba debía determinar la demanda de Fernand Páez de Castillejo acerca de sus cortijos y tierras de Alhondiguilla, sitos en el término de la ciudad ${ }^{46}$. Un mes más tarde figura como veinticuatro de la ciudad ${ }^{47}$. El afianzamiento viene poco

${ }^{42}$ ACC, Libro Verde..., Córdoba, 28 de abril de 1405, y Sección Catálogos. Hospital de San Sebastián, fol. 226rv. Extracto.

${ }^{43}$ ACC, Libro Verde..., Córdoba, 28 de abril de 1405, y Obras Pías, Caja 900, número 8 y Legajo 10, número 33. M. NIETO CUMPLIDO, Op.cit., T. 3 y siguientes, inéditos.

${ }^{44}$ M. NIETO CUMPLIDO, Op.cit., T. 3 y siguientes, inéditos. Archivo familiar Fernández de Mesa, Córdoba, 16 de junio de 1405, A.- Perg. 21 x 27 cm, 3 hojas.

${ }^{45}$ ACC, Libro Verde..., fol. 87r. en el original, p. 110.

${ }^{46}$ (s.l.) (s.d.), 1491, M. NIETO CUMPLIDO, Op.cit., T. 3 y siguientes, inéditos. Archivo General de Simancas (en adelante AGS), Registro General del Sello, número 3.238 , VIII.

${ }^{47}$ Córdoba, 7 de diciembre de 1491. M. NIETO CUMPLIDO, Op.cit., T. 3 y siguientes, inéditos. AHN, Sección Clero, Libro número 2.972, 18 de diciembre de 1497. después, cuando el 25 de enero de 1496, en Córdoba, otorga escritura, junto con su mujer doña Leonor de Angulo, para la fundación de mayorazgo en su hijo Francisco, concesión que le hicieron los Reyes Católicos ${ }^{48}$. Entre las propiedades que pasan a constituir dicho mayorazgo, además de las casas de su morada en la plaza de los Paraísos, se encontraba la heredad de la Alhondiguilla, que se convirtió en el núcleo del término municipal de Villaharta ${ }^{49}$.

En 1497 Juan Pérez de Castillejo fue nombrado jurado de Córdoba en representación de la collación de Santa María ante el cabildo municipal ${ }^{50}$, cargo que le obligaba a vivir permanentemente en la collación de la que era vecino o en otra próxima. Este cargo, en principio electo y a partir de fines del XV transmitido generalmente por heredamiento, fue detentado por la elite social, por lo que en numerosas ocasiones coincidían dentro de la misma familia varios miembros que poseían el cargo de regidores, veinticuatros o alcaldes ${ }^{51}$, como sucedió con los Páez de Castillejo.

48 Córdoba, 25 de enero de 1496, M. NIETO CUMPLIDO, Op.cit., T. 3 y siguientes. ACC, Colección Salazar y Castro, XXXIV, 55.061.

${ }^{49}$ No pocos quebraderos costó a esta familia dicha posesión. En 3 de marzo de 1541 fue presentada una demanda contra Francisco Páez de Castillejo, extensiva a su hijo Luis, porque se había apropiado de las tierras conocidas como la Alhondiguilla, colindante con la venta de Villaharta y el camino a los Pedroches. Estas tierras eran realengas y correspondía su explotación a los vecinos de Córdoba. Se acusaba a Francisco Páez de haber entrado en ellas y haberlas arrendado valiéndose de su cargo como veinticuatro, y se había negado a devolverlas a pesar de habérsele hecho varios requerimientos. M. VILLEGAS RUIZ, La corrupción en Córdoba durante el siglo XVI: (El abuso del poderoso), Sevilla, 2016, pp. 259-284.

${ }^{50}$ Dos años más tarde es ratificado el nombramiento por los Reyes Católicos (J. L. DEL PINO GARCÍA, Op. cit., p. 379).

\footnotetext{
${ }^{51}$ Ibídem, pp. 369-372.
} 


\section{EVOLUCIÓN DEL PALACIO A TRA- VÉS DE SUS VESTIGIOS}

Hasta aquí han transcurrido casi dos siglos desde la primera noticia que tenemos de las casas. Hoy es posible constatar que la distribución de dependencias del palacio se ha mantenido con bastante fidelidad a la que adoptaron las casas cuando se reunieron para configurar el mayorazgo de este linaje. Documento de excepcional importancia para tal fin es la descripción del inmueble existente en el Registro de la Propiedad, de la segunda mitad del siglo XIX:

“La finca urbana o sea casa no 14 antiguo y 2 moderno, situada en la Plazuela de don Gerónimo Páez consta de piso bajo, entresuelo y principal, hallándose distribuido el primero en patio, apeadero y a la derecha de éste una crujía que tiene cuadra y cochera, y a la izquierda crujía con otras cuadras, pozo y granero alto, al fondo galería con dos escaleras, la de la derecha comunica con el piso principal y con salón sobre la cuadra y cochera y subida a una torre; la escalera de la izquierda conduce al entresuelo, compuesto de dos salas, al fondo de esta galería se halla el cuerpo principal del edificio, compuesto de cuatro galerías cercadas, patio con fuente y tres crujías, la crujía derecha tiene tres salas, la de la izquierda dos salas y escusado y la del fondo escalera, sala y sala de paso al segundo patio, en éste una fuente y a la izquierda otro cuerpo de edificio con dos salas, patinillo con pila, fogón, piconera, cocina y otro patio con dos cuartos".

“El piso principal tiene sobre la galería gabinete y sala, sobre el entresuelo tres salas y entrada a un jardín alto con fuente, dos corrales, galería y cocina; comunican estas dependencias y también la escalera de la galería con el cuerpo principal del edificio con análoga distribución que la parte baja".

“Tiene una superficie de $2.682 \mathrm{~m}^{2}$ y le correspondía paja y media de agua de la llamada del Cabildo [...] Constituye casi una manzana y linda por la derecha con la casa no 3 antiguo, 4 moderno de dicha plazue- la con otra $\mathrm{n}^{\mathrm{o}} 15$ antiguo, 8 moderno de la Cuesta de Pera Mato y con la casa no 15 antiguo, 8 moderno de las callejas del Marqués del Villar y por la izquierda y espalda con dichas callejas del Marqués del Villar" ${ }^{52}$.

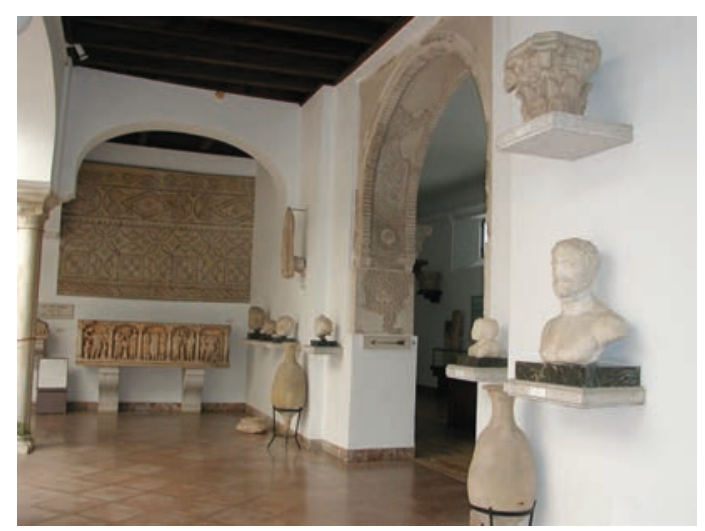

- Fig. 4. Arco mudéjar con yeserías. Patio principal del palacio. Fines del siglo XIV. (C) Museo Arqueológico de Córdoba.

A comienzos del XV, cuando las casas recaen en Ferrán Páez de Castillejo, este las reconstruye, contratando, según Muñoz Vázquez, al albañil Pedro Alfonso ${ }^{53}$, quien vivía en arriendo en una de las casas ${ }^{54}$. Como vestigios de la obra mudéjar podemos citar el arco con yeserías del patio principal (Fig. $4)^{55}$, que pudo estar en relación con alguna puerta a la calle de los Paraísos (del Comendador Moscoso), con una disposición en recodo como se acostumbra en otras casas palaciegas cordobesas (actual convento de Santa Marta, Capuchinas, etc.); en el mismo patio, una ventana geminada (2 $2^{\underline{a}}$ mitad XV) de estilo mudéjar (Fig. 5). Descubierta

\footnotetext{
${ }^{52}$ Registro de la Propiedad, libro 260, finca $n^{\mathbf{0}}$ 643, fol. 206v.

${ }^{53}$ M. MUÑOZ VÁZQUEZ, "Casas solariegas...", p. 48. Algunos documentos de los que cita proceden, según indica, del archivo de don Pedro Criado. Este archivo fue trasladado a Madrid, sin que se sepa su paradero.
}

${ }^{54}$ M. NIETO CUMPLIDO, Op.cit., T. 3 y siguientes, inéditos. ACC, E-IV, 290.

${ }^{55}$ M. Á. JORDANO BARBUDO, El mudéjar en Córdoba, Córdoba, 2002, pp. 213-215. 


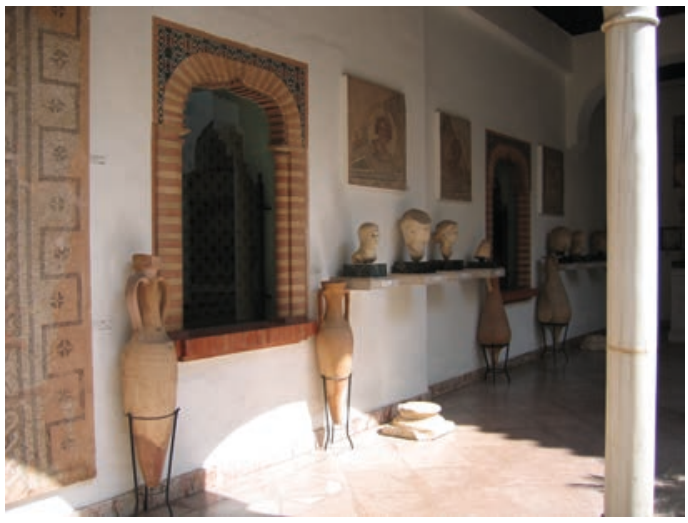

- Fig. 5. Ventana mudéjar. Patio principal del palacio. Siglo XV. (c) Museo Arqueológico de Córdoba.

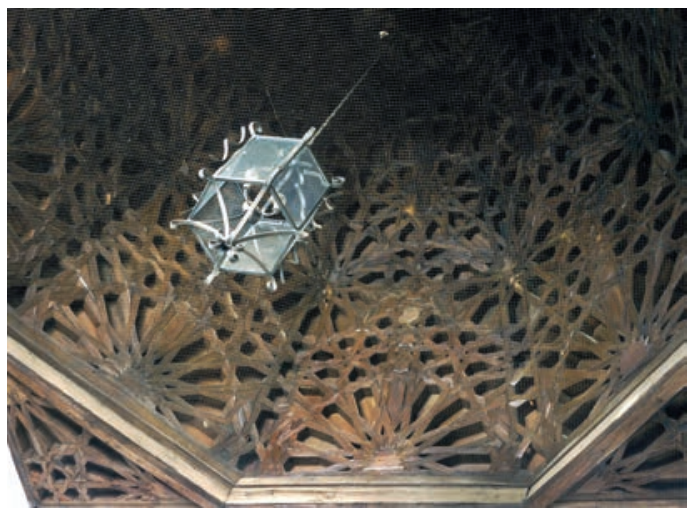

- Fig. 6. Armadura. Escalera principal del palacio. Fines del siglo XV. (c) Museo Arqueológico de Córdoba.

durante la restauración de don Félix, este la tomó como modelo para repetirla en el lado norte. La galería de servicio con cinco arcos mudéjares sobre pilares ochavados y alfices debió servir de acceso al patio alto o "de las mujeres". Finalmente, en la escalera principal se halla la armadura ochavada (Fig. 6).

Según Muñoz Vázquez, la escalera primitiva fue obra de Gonzalo Rodríguez en 1498, siendo propietario de las casas-palacio Fernando Páez de Castillejo ${ }^{56}$, si bien fue reformada por su nieto, Hernán Ruiz II, en 1540 (Fig. 7), al mismo tiempo que hacía la portada ${ }^{57}$. Ciertamente, el diseño y decoración están en consonancia con la estética

${ }^{56}$ M. MUÑOZ VÁZQUEZ, “Casas solariegas...”, p. 50. Cita como fuente el archivo de don Pedro Criado.

\footnotetext{
${ }^{57}$ Ibídem, p. 52.
}

renacentista de la portada. Según el mismo autor, el 12 de abril 1538 lleva a cabo el patio. Las arquerías del piso superior tenían un antepecho labrado que debió desaparecer, pues don Félix encargó uno nuevo (Fig. 8).

Tres de las galerías se cubrieron en planta baja mediante artesonados con piñas pinjantes, restauradas en los años centrales del siglo $X X^{58}$. La cubierta de la sala 11 ha sido atribuida a los carpinteros Alonso de la Plaza y Francisco Muñoz, quienes contratan su factura con don Luis en $1530^{59}$.

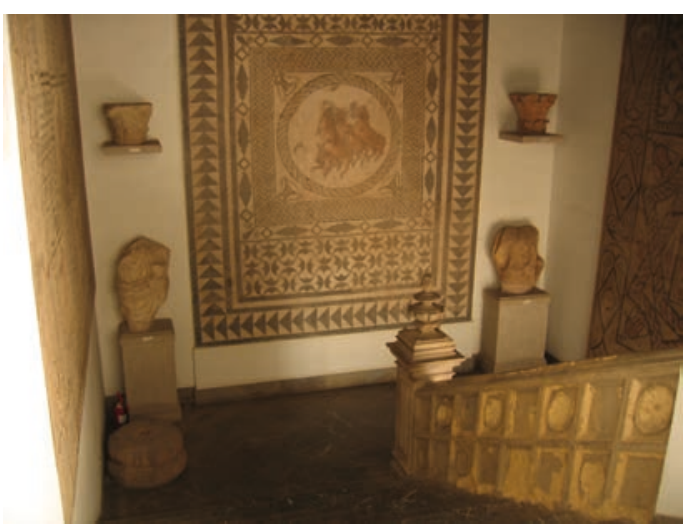

- Fig. 7. Hernán Ruiz II. Escalera principal del palacio. 1540. (C) Museo Arqueológico de Córdoba.

Las últimas casas fueron incorporadas en 1616 por don Diego Páez de Castillejo y Valenzuela, caballero de la orden de Santiago, señor de Villaharta y de la Alhondiguilla, Gentilhombre de Su Majestad ${ }^{60}$, al comprar las situadas a las espaldas de las principales, además de la barrera que las separaba

${ }^{58}$ Ibídem, p. 53.

${ }^{59}$ Ibídem. "También tiene artesonado plano labradas sus alfajías una de las habitaciones que dan al referido patio con igual estilo mudéjar renacentista".

${ }^{60}$ En 1615 Luis de Góngora y Argote le dedicó un soneto de los llamados "dedicatorios", por formar parte de una serie que el célebre escritor dirigió a personajes conocidos del momento, en el que exhortaba al joven don Diego, caballero veinticuatro, a escribir, además de dedicarse al amor (A. COSTA PALACIOS, "Los férreos códigos en perspectiva: posible singularización de los sonetos gongorinos", en M. C. GARCÍA DE ENTERRÍA (ed.), Actas IV Congreso Internacional de la Asociación Internacional Siglo de Oro (AISO), Alcalá de Henares, 1998, vol. 1, p. 461). 


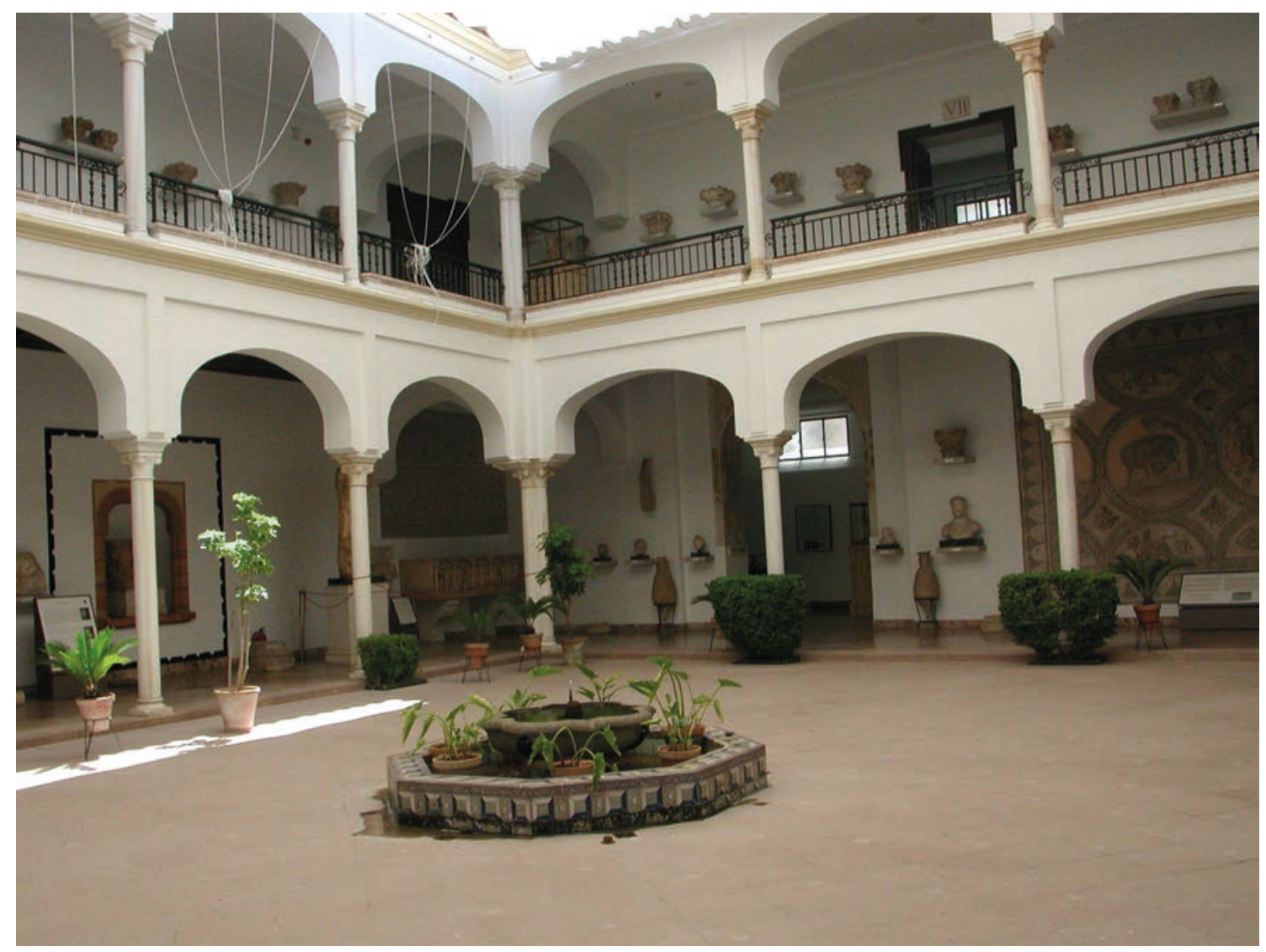

- Fig. 8. Hernán Ruiz II. Patio principal del palacio. 1538. (c) Museo Arqueológico de Córdoba.

(la Costanilla de Baena), que le fue concedida por el cabildo de la ciudad ${ }^{61}$. Al morir sin descendencia, el linaje de los Páez se extinguió en esta rama ${ }^{62}$ y el mayorazgo pasó a don Andrés de Bañuelos Fernández de Mesa $^{63}$ Páez de Valenzuela ${ }^{64}$.

${ }^{61} \mathrm{MACO}$, Notas manuscritas sobre "Casas de Jerónimo Páez", suministradas por don Alfonso Porras Rubio, cit. Archivo Protocolos de Córdoba (en adelante APCO), Oficio 25, Tomo 76, fols. 864r.-865r.

${ }^{62}$ Para seguir el cambio de propietarios hasta la primera mitad del siglo XX, vid. M. MUÑOZ VÁZQUEZ, “Casas solariegas...”, pp. 59-61.

${ }^{63}$ G. J. HERREROS MOYA, “Nobleza, genealogía y heráldica en Córdoba: La casa solariega de los Mesa y palacio de las Quemadas", Historia y Genealogía, 3, 2013, p. 156.

${ }^{64}$ En el Catastro de Ensenada consta que don Pedro de Segovia, clérigo capellán, tenía la mitad de una casa en la plazuela "que llaman de don Gerónimo Páez", que "confronta con las de don Andrés Bañuelos y la obra pía del Santísimo Sacramento de la Santa Iglesia Cathedral" (Archivo Histórico Provincial de Córdoba (en adelante

\section{LA PORTADA. EXALTACIÓN DE LA VIRTUS DEL GUERRERO}

Podríamos decir que el elemento más singular del palacio es la portada (Fig. 9). El contrato se firma el 3 de abril de 1540 entre don Luis Páez de Castillejo -procurador del rey en 1561 y casado con doña Beatriz de Guzmán ${ }^{65}$ - y los maestros Hernán Ruiz II y Sebastián Peñarredonda (Fig. 10) ${ }^{66}$, los cuales fueron estrechos colaboradores durante la etapa inicial cordobesa del primero de ellos. Es de sobra conocido el protagonismo de Hernán Ruiz II, maestro mayor de la catedral cordobesa, en cuanto al asentamiento de modelos italianizantes en Andalucía, así como su formación humanística, según re-

AHPCO), Catastro de Ensenada, Haciendas de Eclesiásticos, T. 2, fol. 838r.

${ }^{65}$ Más noticias en T. RAMÍREZ DE ARELLANO Y GUTIÉRREZ, Op. cit., p. 554.

${ }^{66} \mathrm{Vid}$. anexo para transcripción del texto completo. 
vela su faceta como tratadista ${ }^{67}$. De hecho, el modelo para la portada del palacio lo dio una pintura que le había sido mostrada a don Luis. Es interesante este particular por cuanto refleja la importancia del dibujo a la hora de cerrar el contrato; dibujo que desgraciadamente no nos ha llegado, aunque sí el conocido Manuscrito de Arquitectura de Hernán Ruiz II ${ }^{68}$, que contiene diseños claramente relacionados con el de los Páez, por lo

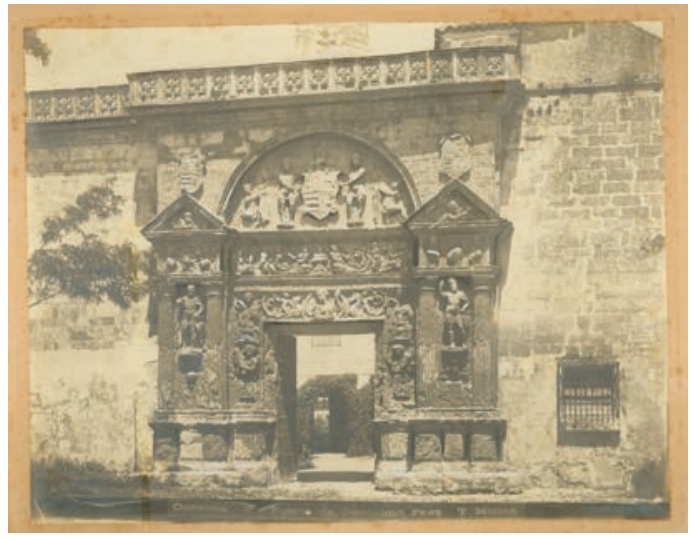

- Fig. 9. Hernán Ruiz II y Sebastián Peñarredonda. Portada del palacio. 1540. (C) Museo Arqueológico de Córdoba.

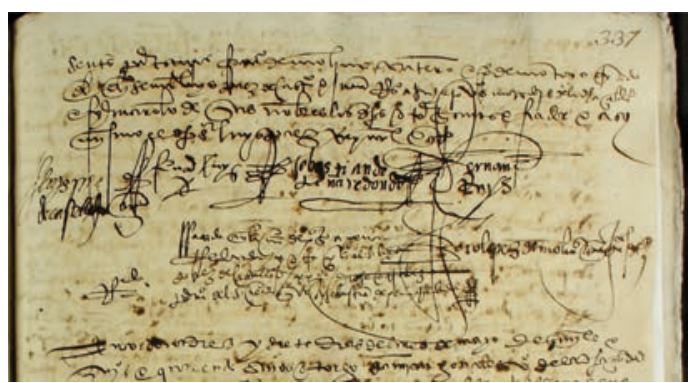

- Fig. 10. Firmas de Luis Páez de Castillejo, Hernán Ruiz I, Sebastián Peñarredonda y Hernán Ruiz II. Contrato de la portada.13 de abril de 1540. AHPCO 12985 P, fols. 335v. y siguientes.

${ }^{67}$ A. DE LA BANDA Y VARGAS, El arquitecto andaluz Hernán Ruiz II, Sevilla, 1974, pp. 85- 91. Véanse, también, las referencias bibliográficas de la nota siguiente.

${ }^{68}$ H. RUIZ, Libro de arquitectura, A. JIMÉNEZ (ed.), Sevilla, 1998. Sobre el manuscrito, cfr. A. DE LA BANDA Y VARGAS, Op. cit., pp. 100-102. Califica la portada de "plateresco atenuado" tendente a fórmulas "Príncipe Felipe", con influencias de Siloe, Machuca e italianizantes. A. J. MORALES, Hernán Ruiz "El Joven",

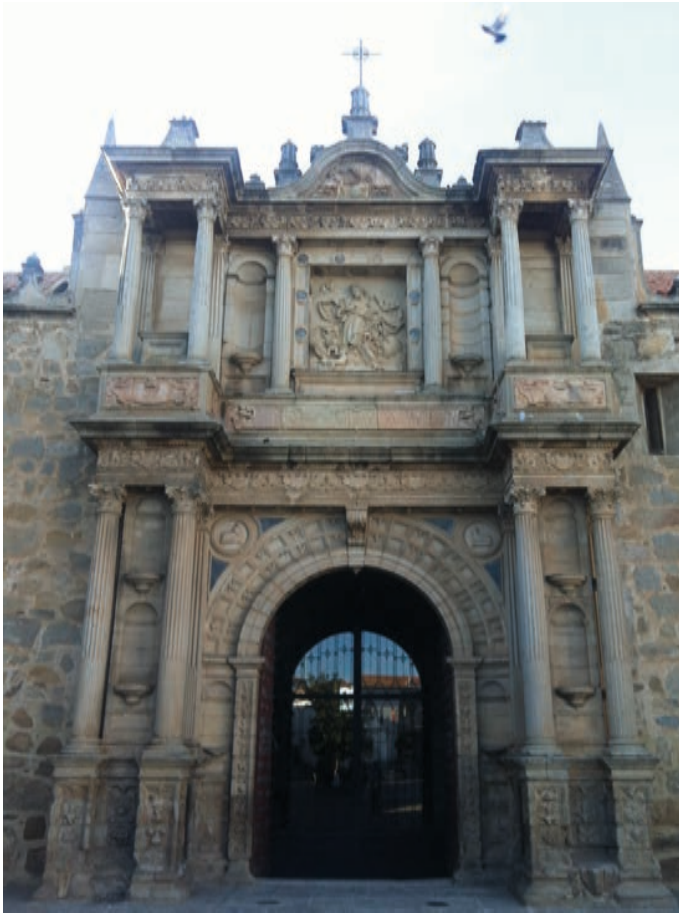

- Fig. 11. Portada de la Iglesia de San Juan Bautista. Hinojosa del Duque (Córdoba). 1539-1571. Foto de la autora.

que tal vez este podría haber estado influido por algún modelo de Serlio, cuyos primeros libros vieron la luz en $1537^{69}$. El hecho es que se puede poner en conexión esta portada con la que había iniciado Hernán Ruiz I y continuado su hijo, Hernán Ruiz II, en la iglesia parroquial de San Juan en Hinojosa del Duque, en $1538^{70}$ (Fig. 11).

Madrid, 1996, pp. 101-103. P. NAVASCUÉS PALACIO, El libro de arquitectura de Hernán Ruiz, el Joven, Madrid, 1974.

${ }^{69}$ Véase a este respecto P. NAVASCUÉS PALACIO, Op. cit., pp. 50 y siguientes, y lámina CXVI. S. SERLIO, Extraordinario libro di Architettura di Sebastiano Serlio, architetto del re christianissimo. Venecia, 1560, consultado el 23 de marzo de 2017. URL: http://www. cervantesvirtual.com/obra/extraordinario-libro-diarchitettura-di-sebastiano-serlio-architetto-del-rechristianissimo--nel-quale-si-dimostrano-trenta-portedi-opera-rustica-mista-con-diuersi-ordini--ventidi-opera-dilicata-di-diuerse-specie-con-la-scritturadauanti-che-narra-il-tutto

${ }^{70}$ Sobre la evolución tipológica de la portada en Córdoba, vid. A. VILLAR MOVELLÁN, “La arquitectura del Quinientos", en M. GUARINOS CÁNOVAS (dir.), Córdoba y su provincia, Sevilla, 1986, pp. 216-218. 
El contrato es denso y de gran riqueza lexicográfica, aportando términos técnicos en ocasiones de difícil interpretación. Resumidamente, viene a exponer las condiciones para la realización de la portada, requisitos, medidas, aporte de materiales, plazos de ejecución y pagos, y, por supuesto, nombre del propietario del palacio, maestros constructores y el fiador. Veámoslo.

La obra no se limitaba a la portada. Había que derribar las paredes viejas de la casa y aprovechar el material para hacer unos ramales de adarve o muro que se levantaría a un lado y otro de la portada, lo cual era lógico al haber justamente detrás un gran patio. Recorriendo la parte superior de la obra iría un andén con un pretil decorado con frisos calados y leones o bestiones con sus caños de hierro para evacuar las aguas; figuras que no se llegaron a poner, aunque el pretil sí luce unas cruces patadas y caladas. Dicho pretil, hacia el interior, habría de hacerse semejante al de la casa del marqués de Priego o incluso mejorando este. Una escalera permitiría acceder al andén. De ese modo se garantizaba el control visual de la plaza y de la ciudad hasta el río, panorámica que también se dominaría desde las torres que flanqueaban la fachada ${ }^{71}$, al estilo de otros miradores coetáneos $^{72}$, pues el "púlpito" o balcón en esquina era muy decorativo, pero pequeño y situado en un nivel más bajo. Conviene reseñar que dicho "púlpito" era una solución que la saga de los Ruiz utilizó también en otros edificios (casa de los Luna, de los Velasco, palacio de Orive).

Gran interés revisten las especificaciones en cuanto a la técnica constructiva. Así, por ejemplo, las juntas habrían de ser cuadradas, con mortero de cal y arena; la acera interior se haría en piedra vieja bien cortada, revocada, con mezcla en proporción de tres partes de tierra y una de cal; $y$, asimismo, cabría destacar cómo se señalan los gruesos de

71 Que ya debían estar erigidas, al menos una de ellas, pues aparece citada en el documento.

72 Caso de la torre mirador de la casa de los marqueses de El Carpio y casa de los Luna, por ejemplo. la obra en ladrillo, si bien hay otras medidas expresadas, como la vara, el pie, el palmo y el dedo.

La portada en sí sobresaldría en planta respecto a los adarves, llevaría cuatro columnas y estaría decorada con salvajes, así como otras figuras de tamaño natural que no se especifican, pues fueron objeto de un contrato con otros artistas, según veremos. Los salvajes se sustituyeron por los guerreros que hoy sostienen el escudo central, verdadero protagonista de la portada, ya que se estipula que, en caso de que pareciera pequeño, el maestro podría elevar la obra y, aunque no se dice, suponemos que sería para aumentar su tamaño.

Se concede gran importancia a la cimentación de la obra, previéndose la construcción de una zanja cinchada con ripio y pisón, mientras que la puerta se obraría con buena cantería nueva, bien labrada y asentada con mortero de cal y arena. Todos estos materiales, además de las maderas para los andamios y las cimbras le serían suministrados al maestro, colocándose en la plaza anexa. En cuanto al pago, se haría en tres partes. Un tercio al empezar, otro una vez terminada la tercera parte de la obra y el resto al concluir las dos terceras partes restantes. Quedaba concertado que el maestro pondría otros maestros, peones y herramientas, como barras, sogas y espuertas. Una vez concluida, la obra sería examinada por los maestros conocedores del oficio que don Luis Páez determinase.

El maestro podría innovar aunque se distanciara del modelo. Se fija como fecha de entrega de la obra el día de san Miguel de 1540. Habida cuenta de que se daría comienzo el 22 de abril, cabe pensar que debieron trabajar con gran celeridad. Ya antes de comenzar habrían cobrado la primera parte de los 122.000 maravedís en que se concertó la obra.

El estrecho vínculo, no solo familiar sino también profesional entre Hernán Ruiz I, maestro mayor de la catedral, y su hijo, Hernán Ruiz II, el Mozo, lo revela el hecho 
de que aquél actuaba en este contrato como fiador. Sus firmas, muy parecidas y tan solo separadas en el manuscrito por la de Peñarredonda, parecen hablar de esa fecunda relación.

Fuera ya de este enjundioso documento, añadiremos que la decoración escultórica fue encargada a Francisco Jato y Francisco de Linares, en tanto que el friso fue ejecutado por Juan de Toribio también en $1543^{73}$.

Según Santiago Sebastián, esta portada sería uno de los primeros ejemplos en España con un programa iconográfico en torno al concepto humanista de la mansión del guerrero $^{74}$. Se situaba en la fachada para rememorar, como ejemplo de virtus, a los dioses y héroes de la antigüedad, programa que con un diseño mucho más ambicioso y cariz religioso se desarrolló en la portada de la Redención, nártex y trasaltar de la mezquitacatedral de Córdoba, que ha sabido interpretar en toda su dimensión Fernando Moreno Cuadro ${ }^{75}$; obra, la del nártex, fechada entre 1543 y 1545 por inscripción y debida a Hernán Ruiz II, por tanto, coetánea de la portada de los Páez de Castillejo. Esta última se concibe casi como un arco de triunfo, al igual que la de la Redención. El medio punto alberga a dos tenantes que flanquean el blasón, timbrado por un casco adornado con lambrequines. Junto a estos tenantes, unos centauros sostienen sus escudos ${ }^{76}$. Cabría, también, establecer relación con la representación del escudo del obispo don Leopoldo de Austria -tío de Carlos V- en el frontis

${ }^{73}$ Datos que aporta M. Muñoz Vázquez referidos al archivo de don Pedro Criado ("Casas solariegas...", p. 55).

${ }^{74}$ S. SEBASTIÁN, Arte y humanismo, Madrid, 1978, p. 81.

${ }^{75} \mathrm{~F}$. MORENO CUADRO, "El crucero de la catedral de Córdoba. Estudio iconográfico e iconológico", monográfico de Cuadernos de Arte e Iconografía, XVI, 31, 2007, pp. 30-32, 98-100.

${ }^{76}$ La mala calidad de la calcarenita ha ocasionado un deterioro muy avanzado del conjunto que dificulta y en algunos casos imposibilita la identificación de motivos.

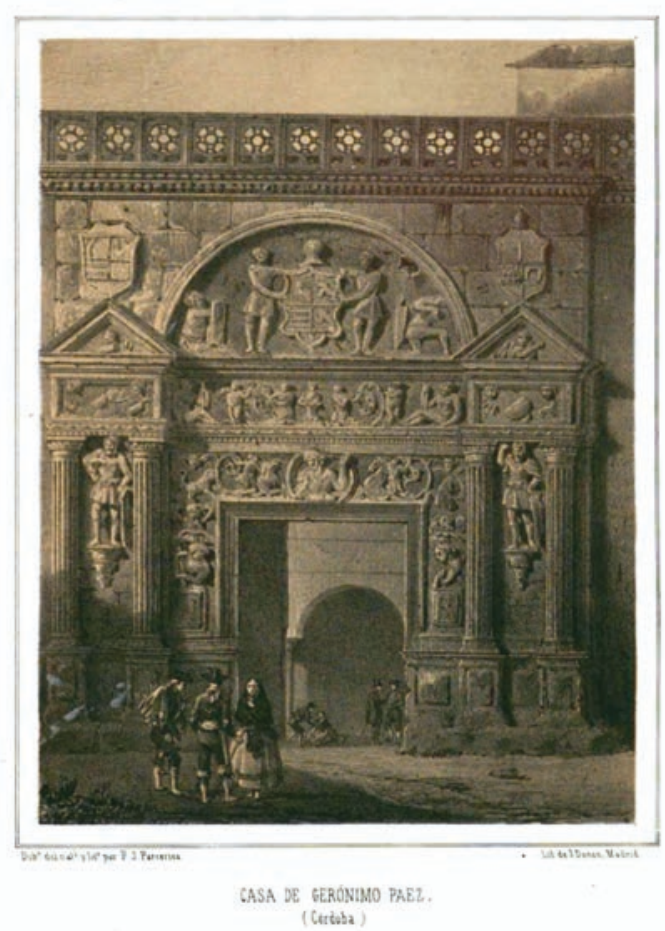

- Fig. 12. Francisco Javier Parcerisa. Casa de Gerónimo Páez. En P. MADRAZO, Recuerdos y bellezas de España, Madrid, 1855, p. 406.

próximo a la portada de la Redención, realizado por el mismo maestro y quizás también por Peñarredonda ${ }^{77}$. La presencia de jinetes y lanceros podrían estar aludiendo a la defensa de la fe frente a los reformistas, pues estuvo a punto de ir al segundo encuentro en Trento ${ }^{78}$.

Sebastián identifica con ciertas dudas los dos personajes que flanquean la portada, tratándose, según él, de Escipión y Alejandro Magno. Igualmente, sugiere que las dos figuras que hay por encima cobijadas por frontones serían Hércules, a la izquierda, y

77 J. ARANDA DONCEL, "La familia del emperador: Leopoldo de Austria, obispo de Córdoba", en M. RIVERO RODRÍGUEZ y A. ÁLVAREZ-OSSORIO ALVARIÑO (coords.), Carlos V y la quiebra del humanismo político en Europa (1530-1558), vol. 2, Madrid, 2001 p. 417.

${ }^{78}$ Ibídem, pp. 408-409. Curiosamente, el veinticuatro Luis Páez de Castillejo defendió en el concejo de febrero de 1544 que don Leopoldo pudiera cazar en la Alameda del Obispo, ante una denuncia presentada contra este (Ibídem, p. 418). 
enfrente Teseo, ambos caracterizados por la maza (Fig. 12).

En el entablamento se representan dos parejas de personajes sentados o recostados y putti. Otros elementos repartidos por la portada son los propios de la panoplia para aludir a los hechos de armas. En nuestra opinión, las alegorías de las virtudes cardinales que deben adornar al buen guerrero -no identificadas hasta ahora- completan el mensaje iconográfico. Así, en el tondo que preside el dintel de la puerta, una mujer sujeta en la mano izquierda un objeto posiblemente un espejo- y en la contraria lo que parece ser un freno. En tal caso, podría tratarse de una doble alegoría de virtudes, la prudencia -el espejo- y la templanza -el freno-, que ayuda a sujetar las pasiones. Dos putti se aproximan a ella sobre caballos cuyas colas se transforman en guirnaldas.

En las jambas hay otras dos figuras femeninas de medio cuerpo. La de nuestra izquierda sostiene un trozo de columna, que identificamos como la Fortaleza, mientras que la opuesta se inclina hacia ella elevando el brazo diestro, posiblemente empuñando la espada que ha desaparecido, siendo en tal caso la Justicia. Sendos yelmos con lambrequines por encima de estas dos figuras acentúan el carácter militar del mensaje.

El modelo de virtus viene del modelo del caballero medieval (miles Christi), solo que ahora en el Renacimiento pasa por el filtro del clasicismo. Se exaltan las acciones bélicas que han llevado al linaje a la gloria, pero también las virtudes que deben adornar al caballero para aspirar a ella. La representación de emperadores romanos y dioses o héroes de la antigüedad no era casual; pretendía glorificar al titular del mayorazgo y a su linaje, digno de equipararse a los héroes clásicos. Hércules era símbolo de la virtus, un modelo a seguir; adoptado por los monarcas hispanos como ascendiente ${ }^{79}$.

\footnotetext{
${ }^{79}$ Véase a este respecto F. MORENO CUADRO, Op. cit., pp. 56-62.
}

El programa iconográfico se completa con la representación heráldica ${ }^{80}$. El interés que despertaron las armas nobiliarias en las portadas se advierte en Sebastiano Serlio, quien en Los libros de arquitectura le dedica el capítulo "De las maneras de las armas de las casas nobles y de sus genealogías", en el que indica que el arquitecto debe saber la genealogía del comitente, para que no las haga falsas y sepa dónde deben ir colocadas ${ }^{81}$.

\section{CONCLUSIONES}

La evolución de estas casas culmina con la fábrica de una de las mejores portadas de la arquitectura civil del humanismo dentro del Renacimiento cordobés, con uno de los programas iconográficos más completos conservados de estas características en la provincia, que tiene como finalidad la exaltación del linaje de los Páez de Castillejo. Se trata de un eslabón más en la evolución tipológica en la transición de la Edad Media a la Edad Moderna y su realización fue el culmen de una importante transformación urbanística que ha continuado hasta la actualidad. Todo esto invita a hacer una reflexión sobre la conservación del patrimonio, pues urge la restauración del palacio, así como una intervención que detenga el progresivo deterioro de la portada.

\section{APÉNDICE DOCUMENTAL}

Córdoba, 13 de abril de 1540.

AHPCO, Escribanías Públicas de Córdoba, Oficio 20, Protocolo del escribano Pedro López de Molina, 12985P, fols. 334v.337r.

\footnotetext{
${ }^{80}$ M. Á. JORDANO BARBUDO, Escudos de Córdoba y provincia en fachadas y portadas, Córdoba, 2013, pp. 124129.

${ }^{81}$ Alude a la concesión de escudos a los capitanes de ejércitos como reconocimiento a su labor, como se hacía en la Antigüedad, cuando se erigían estatuas para recordar a determinados personajes por su virtud (S. SERLIO, Libros de la arquitectura, Toledo, 1552, T. 4, fol. LXXVIIv.).
} 
Contrato entre Luis Páez de Castillejo, de un lado, y los maestros Hernán Ruiz II y Sebastián Peñarredonda, de otro, para la realización de la portada de su casa palacio.

A. Extracto en M. MUÑ̃Z VÁZQUEZ, "Casas solariegas...", pp. 54-55.

"Sepan cuantos esta carta bieren como yo Fernan Ruiz cantero hijo de Fernan Ruiz maestro mayor de la Santa Yglesia de la muy noble e muy leal cibdad de Cordoba y becino en la collacion de Santa Salvador y Sebastian de Peñarredonda e otros canteros vecinos de la dicha cibdad en la collacion de Santa María otorgamos y conocemos que somos conbenidos e contratados con el noble caballero don Luis Paez de Castillejo veinte y cuatro de la dicha cibdad ques presente de tomar e tomamos a nuestro cargo e diseño la labor y obra de una portada ques del dicho don Luis Paez de Castillejo quiere y manda hacer en las casas de su morada conforme a la pintura de una muestra quel dicho señor Luis Paez e Castillejo tiene de nuestro poder en pergamino y a las condiciones que entre unos y otros se an platicado que son las siguientes.

Primeramente el maestro o maestros que desta obra se encargue a de hacer una portada con dos rramales de adarbe de una parte y otra conforme a la muestra a de tener de ancho la portada treinta pies y los ramales a beinte pies dos y tres pies mas o menos con su arbo a la esquina conforme a la muestra y todo lo enlebado de toda la torre a de ir de frisos como de calados y bestiones y todo lo demas e molduras todo lo a de hacer el maestro al contento de su merced y lo grueso de la portada a de ser del ancho que se le mandare y en todas las alturas de la puerta así en el grueso como en toda la obra sea conforme el maestro con los tamaños de la muestra y el encarnamento a de bolar afuera del adarbe conforme a la muestra un ladrillo y medio con los encarnamentos altos y bajos y todo lo demas asi en la obra como en las salidas y pleytiles se rremita a las condiciones de la dicha muestra. A de dar y parar este encarnamento con los pleytiles en la conpostura de la puerta y de fuera destos an de ir las cuatro colunas con sus salvajes en medio de laltura con esa medida fuese contento no siendo cosa demasiada a de tener el dicho adarbe en alto siete baras de maçiço sin el pleytil y el adarbe de la puerta diez baras sin el pleytil y si despues de trazada la portada asi le pareciera que el escudo de enmedio fuese pequeño que el maestro suba la obra y la enpine fasta en cabo del pleytil para concertarse con la boluntad de su merced y en todo lo demas en alturas y gorduras de colunas y molduras se conforme el maestro con la dicha muestra como dicho es con tanto que las figuras sean del tamaño del natural y los dichos frisos que pone la muestra a de ser cada uno de una bara en alto por lo menos y de un palmo de rreliebe y todos los bestiones que estan trazados en la dicha muestra correspondan al tamaño de las figuras.

Iten el maestro haga zanjas a su costa de longo a longo y de syete pies en ancho y mas la salida de la puerta de la hondura que conbiniere para que la obra sea segura y firme y las buelba a çinzar de ripio y pison y buena mezcla con sus ripios hasta un pie abajo del suelo de la calle a su costa del maestro y esto hecho haga el maestro una hilada de repa de seis ladrillos de grueso en las salidas de la puerta e forme en cima la dicha portada con su adarbe de una parte y otra de cinco ladrillos de grueso sin el berdugo o moldura que a de llebar cinco dedos de salida y bara y media en altura contra el marmol de la ezquina llebando en lo alto del pleytil un pulpito fecho que este en la esquina que mire a un cabo y otro conforme a la muestra con un bestion sobre el que poner en que durema y se sostiene el dicho pulpito. Yten demas de los dos rramales que estan en la muestra el dicho maestro a de hacer otro rramal de adarbe a la mano derecha de la puerta de forma y manera que los otros dos ramales de la muestra y de la misma altura de siete tapias de maçico y gordura de cinco ladrillos hasta llegar a la ezquina de la casa donde moran los valencias y este a donde a de salir con el paño de la pared de la dicha casa y donde fina e entran la en las gorduras de la pared de manera que el ala del tejado cargue 
sobre lo nuebo y para hacerla a de ribar el maestro las paredes y allanar el suelo para hacer las zanjas segun dicho es y este ramal no a de llebar pleytiles ni encarnaduras por de dentro.

Iten dicho maestro a de hacer otros dos ramales de pared la una desde el esquina del pulpito asta la ezquina vieja que esta frontero de las casas del doctor Tomas y el otro desde donde remata el adarbe de la mano derecha de la puerta hasta llegar a la esquina de un palacio que esta cerca del pozo las cuales dichas paredes han de ser de dos tapias en alto del anterior de cimiento de la misma forma de los otros cimientos con su chaflan y sobre esta su tapierra la cual con el cimiento a de tener siete baras en alto y dos ladrillos y medio de grueso y ambas paredes donde fenescen se entreguen con las biejas de albañileria.

Iten an de subir los dichos adarbes con la puerta de buena canteria nueba y muy bien labrada e bien asentada en cal y arena e trabada y con el altura que lleban a la puerta de rivas del adarbe se hagan subida y escalera para subir al anden de la puerta la cual escalera no a de ponerse por dentro ni por de fuera y a de yr este adarbe una hilada de adornicho y otra de bote y en cada hilada un ratundo y hecho enrrasado lo sobredicho con sus pleytiles de una parte y otra asiente el maestro de a quince pies una de la otra gonforas de figuras de leones o bestiones con sus caños de fierro por arma y el dicho anden que queda de seys ladrillos de ladrillo de rebocado y rascado asentado en cal y arena solado con sus corrientes a los caños y la encarnadura y el pleytil de parte de dentro a de ser como lo de la casa del señor marques de Priego y antes mejor que peor.

Iten toda esta dicha obra a de yr asentada en cal y arena con juntas cuadradas y la acera de dentro de piedra bieja bien cortada e rebocada y la ripiazon de esta mezcla a tres de tierra y una de cal y el rebate de las puertas a de tener un ladrillo y medio de grueso de manera que bengan en caçar las puertas y el grueso del adarbe en manera para mas de piedra de dos ladrillos de bolsura e la portada debe ir asentada en asiento delgado y limpio y bien retondido y las puertas despues de asentadas se an de enbeber en el grueso del adarbe de la portada e por la parte de dentro an de quedar formados sus remates. Yten quel maestro que desta obra se encargue le daran suministrados todos los materiales que en la obra se ubieren de quedar alrededor de la portada en la plazuela e maderas para andamios y cimbras e los maravedis por que la obra se remate en tres tercios uno luego para empezar e otro fecha el un tercio de la obra el otro tercio hechas las dos partes de la obra para acaballa pagando en dos veces de manera que la obra acabada este pagada y el maestro ponga maestros $\mathrm{y}$ peones y herramientas de todas suertes y barras y sogas y espuertas y todo lo demas para hacer su obra e deje el maestro bien hecha y acabada a bista de los maestros que su merced mandase que la vean viendo sabidores del oficios y cuando la obra finare a bista del maestro escogido por su merced y el otro por el maestro que face la obra.

Iten que puede el maestro ynovar obra en algunos lugares que venga bien aunque se separe algo de la muestra tal que no sea de menos condicion en valor y en parescer y si sucediera lo a de emedar e obrar de otra manera que el maestro lo faga tanto que sea longo y deslongo por vista de oficiales fasta la acabar dandole recaudo de materiales y dineros como dicho es.

Iten que la dicha obra la den fecha y acabada de todo punto y con perfeccion que ha de tener conforme a la muestra y estas dischas condiciones para el dia de sant Miguel de setiembre deste presente año de mil quinientos y cuarenta años y que la comienzan a veinte dias del mes de abril y cuatro dias antes se haga la primera paga.

Iten el maestro o maestros que desta obra se encargasen an de derribar las paredes biejas de la calle y esas otras que afora estan fasta el suelo para aprovecharse de la tierra para facer mezclas y tapias y de la piedra para rripiazon de la dicha obra. 
Iten que los pleytiles y encarnamentos an de ser conforme a la muestra y de cinco cuartos de alto el pleytil sin el carnamento por manera que desde el suelo del terrado fasta el pleytil aya las dichas cinco cuartas. Conforme a los cuales dichas condiciones que de suso van encorporadas y a la pintura que dicha es y en ellas se face mincion mas los dichos Fernan Ruiz y Sebastian de Peñarredonda canteros por esta presentacion otorgamos $\mathrm{y}$ prometemos de facer $\mathrm{y}$ de dar fecha y acabada de todo el punto y perfeccion la dicha portada en las casas de la morada de vos el dicho señor Luis Paez de Castillejo vente y cuatro dentro del termino asignado y declarado a las dichas condiciones que vos el dicho señor Luis Paez de Castillejo se aya obligado a nos dar y pagar y deys y pagueys por el facer la dicha portada y rramales y todo lo demas que somos obligados a labrar conforme a las dichas condiciones ciento y dos mil maravedis puestos y pagados en esta cibdad a su fuero y jurisdicion a los plazos declarados en las dichas condiciones conforme a las cuales otorgamos e prometemos de comenzar y comenzaremos la dicha obra desde el dicho veinte de este presente mes de abril y año de la fecha y de no partar mano della fasta la acabar y dar acabada por el dicho dia de sant Miguel de setiembre venidero so pena de cien mil maravedis por vos, con vos y para con vos el señor don Luis Paez de Castillejo ponemos en lugar seguro la dicha pena el dicho señor Luis Paez podais mandar faser con estos maestros la dicha obra fasta la acabar conforme a la dicha muestra y condiciones y somos obligados y nos obligamos a facer y cumplir lo contenido esta dicha obligacion y condiciones en ellas encorporados y damos por fiador a Fernan Ruiz cantero maestro mayor de las obras de la santa yglesia desta cibdad padre de mi el dicho Fernan Ruiz e otrosi vecino de la dicha cibdad que esta presente y yo el dicho Fernan Ruiz maestro mayor que he sido e soy presente y e oydo y entendido las dichas condiciones y e bisto la muestra y pintura conforme a la que se a de facer la dicha portada y la dicha obliga- cion por el dicho Fernan Ruiz mi fijo y Sebastian de Peñarredonda fecha y otorgada y todo lo demas que de suso se face mincion conozco e otorgo que fio a los suso dichos y cada uno de ellos que por dichos ciento dos mil maravedis fagan la dicha portada en las casas del dicho señor don Luis Paez de Castillejo segun y como dicho es que se hace mincion la dicha obligacion y si no lo ficieren e cumplieren que yo como su fiador lo fare cumplir e pagar e pagare por todo lo cual asi Ruiz el Moço y Sebastian de Peñarredonda como principales e yo el dicho Fernan Ruiz cantero mayor como fiador de los suso dichos todos tres de mancomun y cada uno de nos por el todo obligamos nuestras personas e bienes raices e muebles abidos e por aber e damos poder complido a todas ygules que instancias asi de la dicha obligacion como de otras partes y cumplir todo lo asentado bien como si fuere para si e yo el dicho Luis Paez de Castillejo veinte y cuatro de Córdoba que por suso dicho e sido e soy presente otorgo que me obligo por vos los sobredichos hechos que se contienen e me obligo de pagar los dicho ciento e dos mil maravedís por la dicha obra a los plazos sobredichos y de dar todos los dichos materiales que se an dicho y me obligo mis bienes en presencia de mi el escribano publico otorgado en Cordoba a trece dias del mes de abril del año de Nuestro Salvador J. C. de mil quinientos cuarenta años al otorgamiento fueron presentes por testigos Francisco de Molina cantero y Pedro de [...] criado del dicho señor Luis Paez de Castillejo.

Firman: Luis Paez de Castillejo, Fernand Ruys, Sebastian de Peñarredonda y Fernan Ruiz.

\section{BIBLIOGRAFÍA}

ARANDA DONCEL, J., "La familia del emperador: Leopoldo de Austria, obispo de Córdoba", en M. RIVERO RODRÍGUEZ y A. ÁlVAREZ-OSSORIO ALVARIÑO (coords.), Carlos $V$ y la quiebra del humanismo político en Europa (1530-1558), vol. 2, Madrid, 2001. 
BAENA ALCÁNTARA, M. D., "El teatro romano de Córdoba", Mus-A: Revista de los museos de Andalucía, 2, 2003, pp. 157-161.

, "El Museo Arqueológico de Córdoba. Un museo en transformación", Museos.es, 7-8, 2011-2012, pp. 308-319.

BANDA Y VARGAS, A. de la, El arquitecto andaluz Hernán Ruiz II, Sevilla, 1974.

CASTILLEJO CUENCA, M. I., “Los caballeros Veinticuatros de Córdoba a finales del siglo XVII", Chronica Nova, 22, 1995, pp. 29-71.

COSTA PALACIOS, A., "Los férreos códigos en perspectiva: posible singularización de los sonetos gongorinos", en M. C. GARCÍA DE ENTERRÍA (ed.), Actas IV Congreso Internacional de la Asociación Internacional Siglo de Oro (AISO), Alcalá de Henares, 1998, vol. 1., pp. 459-468.

DÍEZ JORGE, M. E., El arte mudéjar: expresión estética de una convivencia, Granada, 2001.

ESCOBAR CAMACHO, J. M., "Notas sobre el repartimiento de Córdoba", Boletín de la Real Academia de Córdoba, LV, 107, 1984, pp. 161-171.

Córdoba en la Baja Edad Media. (Evolución urbana de la ciudad), Córdoba, 1989.

HERREROS MOYA, G. J., “Nobleza, genealogía y heráldica en Córdoba: La casa solariega de los Mesa y palacio de las Quemadas", Historia y Genealogía, 3, 2013, pp. 99-194.

JORDANO BARBUDO, M. Á., El mudéjar en Córdoba, Córdoba, 2002.

Escudos de Córdoba y provincia en fachadas y portadas, Córdoba, 2013.

MORALES, A. J., Hernán Ruiz "El Joven", Madrid, 1996.

MORENO CUADRO, F., "El crucero de la catedral de Córdoba. Estudio iconográfico e iconológico", monográfico de Cuadernos de Arte e Iconografía, XVI, 31, 2007.

MUÑOZ VÁZQUEZ, M., "Historia del repartimiento urbano de Córdoba", Boletín de la Real Academia de Córdoba, XXXII, 81, 1961, pp. 71-94.

“Casas solariegas. Palacio de los Páez de Castillejo, Plaza de los Paraísos y Cuesta de Peramato", Boletín de la Real Academia de Córdoba, 84, 1962, pp. 247-279.

MURILLO, J. F. y ARAQUE, F. A., “Informe preliminar de las excavaciones arqueológicas realizadas en el solar destinado a ampliación del Museo Arqueológico Provincial de Córdoba", Anuario Arqueológico de Andalucía 1987, III, Actividades de urgencia, 1990, pp. 203-204.

NAVASCUÉS PALACIO, P., El libro de arquitectura de Hernán Ruiz, el Joven, Madrid, 1974.

NIETO CUMPLIDO, M., Corpus Mediaevale Cordubense, T. 3 y siguientes, inéditos.

PINO GARCÍA, J. L. del, “El concejo de Córdoba a fines de la Edad Media: estructura interna y política municipal", Historia. Instituciones. Documentos, 20, 1993, pp. 355-401.

RAMÍREZ DE ARELLANO Y GUTIÉRREZ, T., Paseos por Córdoba, o sean apuntes para su historia, Córdoba, 1973.

RUIZ, H., Libro de arquitectura, A. JIMÉNEZ (ed.), Sevilla, 1998.

SÁNCHEZ VELASCO, J., “El acceso Norte al teatro romano de Córdoba: secuencia estratigráfica y estudio de materiales", Anales de Arqueología Cordobesa, 10, 1999, pp. 115-159.

SEBASTIÁN, S., Arte y humanismo, Madrid, 1978.

SERLIO, S., Libros de la arquitectura, Toledo, 1552.

VENTURA, Á., "La recuperación de la Córdoba romana: los edificios de espectáculos", en T. NOGALES BASARRATE (coord.), Vivir las ciudades históricas, Coloquio Internacional sobre ciudades modernas superpuestas a las antiguas, 10 años de investigación, Mérida, 1997, pp. 33-54. 
VENTURA, Á. et alii, “Análisis arqueológico de la Córdoba romana: resultados e hipótesis de la investigación" en P. LEÓN (ed.), Colonia Patricia Corduba. Una reflexión arqueológica, Córdoba, 1996, pp. 87-118.
VILLAR MOVELLÁN, A., “La arquitectura del Quinientos", en M. GUARINOS CÁNOVAS (dir.), Córdoba y su provincia, Sevilla, 1986.

VILLEGAS RUIZ, M., La corrupción en Córdoba durante el siglo XVI: (El abuso del poderoso), Sevilla, 2016. 